\title{
Who will fashion the distant future?
}

Two large companies, IBM in the United States and ICI in Britain, suddenly look vulnerable. Is the explanation their sheer size or, more probably, their ingrained habits?

INTERNATIONAL Business Machines (otherwise IBM) is one of the largest companies in the world. Its annual turnover is greater than the gross domestic product of many substantial nation states, Belgium for example. Apple Computer, by contrast, is one of the youngest and, according to legend, began life in a garage just over a decade ago. Why should these two very different companies be planning a joint venture that, they hope, will fashion for us computers of a radically different kind a few years from now (page 98)? And will they succeed? What, for that matter, explains the present fuss in Britain, where Imperial Chemical Industries (ICI), one of the largest indigenous companies and one of the most technically advanced, is behaving like a rabbit transfixed in the face of the threat implied by the purchase of nine per cent of its shares by Hanson Industries, a largely financial organization that has made its successful way in the world by buying other companies and selling their bits and pieces separately?

There is a sense in which both IBM and ICI are victims of their own success. Until a decade ago, when its first personal computers appeared in the shops, IBM was the world's predominant supplier of mainframe computers. It had won a superb reputation for keeping this complicated machinery at work, but, perhaps for that reason, it was slow to recognize how far the personal computer would change the world. Then, having become the chief provider of personal computers worldwide, it was slow to appreciate that its customers would come to demand ever greater amounts of immediate and long-term memory, intellectually more transparent computer chips and machines on people's desks that would match the power of its own chief products - mainframes hallowed over years. So, last breathtaking week, IBM has jumped into three entirely novel joint ventures - an arrangement that Wang Laboratories should sell chiefly IBM computers, joint European production of memory chips with Siemens and the Apple venture (Department of Justice allowing).

ICI's problem is similar in origin, but the solution is not immediately apparent. Although British-based, ICI is international in scope. Also like IBM, the thoroughness of ICI's technical backing for its products has won it an enviable reputation. But, like all conglomerates, ICI's financial performance is necessarily an average of the performance of its divisions, some of which are pretty unglamorous in the middle of a recession. For several years, ICI has been trying to back out of well-established ventures that add relatively little value to the cost of the raw materials they employ, but without enough success. The high-value end of the business, on the other hand, is in pharmaceuticals, which is a notoriously high-risk business. A decision to put all its eggs in that basket would not have won the company many new friends.

So does it follow that all big companies are as vulnerable as IBM (in a quickly changing market) and ICI (hurt by the recession)? Not necessarily. If the threat to ICI is that Hanson might buy the whole company (at about $£ 12,000$ million at this week's stock market price) and then sell the pieces at a profit, the company itself could in principle do the same, providing a similar profit for its shareholders. The casualties of that process would be the corporate culture (which is unimportant) and the common services that the various divisions enjoy, of which research and development is the most important. It would be a great misfortune for ICI's separate enterprises, and for Britain as a whole, if its substantial research and development effort were sacrificed on the alter of immediate profit as a successful Hanson bid would almost certainly entail. The other side of that coin is that big companies such as this, which have the opportunity, also have a responsibility to see that their research does even better than that of smaller companies. Despite its long record in the field, that is where ICI should have done better in the past fifteen years.

IBM's difficulty is different in kind. The sheer physical inertia that has prevented it from responding as quickly as it might have done to novel challenges is only part of the explanation. Over the past fifteen years or so, it has been compelled to make choices between different paths of development for fear of creating circumstances in which different parts of the same company were competing with each other. To have been selling cheap high-capacity machines when Sun Microsystems began (in the early 1980s) would have seemed a corporate nonsence, as it would have been to have embraced both the UNIX operating system and IBM's own version of the DOS based systems. But would that necessarily have been the case? Would motor-car manufacturers equipped to make and sell invalid carriages be thought foolish if they also sold sports cars? Backing all possible horses would have been a better bet for such a giant than the small-company trait of making risky choices. 